\title{
ANÁLISE DA PERCEPÇÃO DOS MORADORES DE SÃO SEBASTIÃO DE LAGOA DE ROÇA (PB) QUANTO A REDUÇÃO, REUTILIZAÇÃO E RECICLAGEM DE RESÍDUOS SÓLIDOS
}

\author{
Luana Andrade Lima Querino ${ }^{1}$ \\ Jógerson Pinto Gomes Pereira ${ }^{2}$ \\ Mara Karinne Lopes Veriato Barros ${ }^{3}$
}

Resumo: A quantidade de resíduos gerados continua a aumentar devido ao desenvolvimento crescente e o estilo de vida moderno. Diante desse quadro a pesquisa se propôs a investigar como pensam e se comportam os moradores de Sebastião de Lagoa de Roça/PB em relação à geração e reutilização dos resíduos domiciliares; a partir de uma de pesquisa fundamentada em uma abordagem qualiquantitativa e explicativa com caráter descritivo, cuja coleta de dados foi feita a partir de entrevistas semiestruturadas que demonstraram que a maioria dos pesquisados possui percepção confusa, referente a redução, reutilização e reciclagem dos resíduos, não percebendo as inter-relações entre ações, hábitos e os possíveis impactos sobre o ambiente natural e social.

Palavras-Chave: Consumo; Resíduos Domiciliares; Impacto.

${ }^{1}$ Universidade Federal de Campina Grande (UFCG). E-mail: Iuanaandradelima@gmail.com

2 Universidade Federal de Campina Grande (UFCG). E-mail: jogerson@deag.ufcg.edu.br

${ }^{3}$ Universidade Federal de Campina Grande (UFCG). E-mail: karinnelv@yahoo.com.br. 


\section{Introdução}

Os resíduos sólidos urbanos constituem uma preocupação da sociedade contemporânea, a crise ambiental reflete a falência dos modelos atuais de utilização e gerenciamento de tais resíduos.

Os sistemas naturais e sociais têm convivido com vários problemas relacionados aos resíduos sólidos, os quais concorrem ao aumento e a variedade de materiais descartados. A quantidade de resíduos gerados continua a aumentar devido ao desenvolvimento crescente e o estilo de vida moderno, acentuando os problemas de desperdício, associado ao crescente uso de embalagens descartáveis compostos por materiais plásticos.

A Conscientização individual sobre os problemas ambientais e a importância do gerenciamento dos resíduos faz-se imprescindível, uma vez que o envolvimento dos cidadãos com a problemática é a forma ideal de estimular a sua participação na adoção de atitudes que contribuam para a sustentabilidade do processo de gerenciamento dos resíduos (TÂRTIU, 2011, p.263-276). Entretanto as práticas básicas de gestão de resíduos sólidos são muitas vezes negligenciadas a nível individual (VIVEK et al., 2013, p. 147-150).

Tadesse, Ruijs e Hagos (2008, p.2), salientam que o envolvimento da população tem grande importância na garantia da eliminação adequada dos resíduos. Apesar da deposição inadequada dos resíduos sólidos trazer consequências graves e até mesmo o serviço de limpeza urbana realizar a coleta domiciliar de resíduos diariamente, é comum encontrar pelas ruas da cidade de São Sebastião de Lagoa de Roça resíduos domésticos dispostos inadequadamente em vários pontos periféricos da cidade.

Estudo realizado por Diniz (2011, p. 42-43) destaca que $40 \%$ dos resíduos produzidos no município são depositados pelos moradores da cidade a céu aberto. Estes não se dão conta, do risco e dos impactos gerados para o meio ambiente e dos transtornos para a população como um todo.

O estudo da percepção ambiental é de fundamental importância, sendo possível conhecer a cada um dos envolvidos, facilitando a realização de um trabalho com bases locais partindo da realidade do público alvo, para conhecer como os indivíduos percebem o ambiente em que convivem (FAGGIONATO, 2014 , p.1). Sendo assim para a promoção da conservação ambiental deve se levar em conta o comportamento e as ações dos seres humanos.

Nesse contexto, estudos com esse escopo dão contribuições importantes para investigá-la as relações dos indivíduos com o ambiente em que vivem, refletindo o bem-estar e a qualidade de vida. Diante do exposto, a pesquisa propõe investigar o que sabem, como pensam e se comportam os moradores de Sebastião de Lagoa de Roça em relação à geração e reutilização dos resíduos domiciliares produzidos diariamente? 


\section{Resíduos Sólidos Urbanos}

A questão dos resíduos sólidos no Brasil foi durante muito tempo colocado em segundo plano. $O$ intenso processo de urbanização associado à carência de investimentos na área do saneamento levou à proliferação de lixões pelo país. Com o agravamento dos problemas socioambientais, a temática dos resíduos foi colocada nas discussões sobre saneamento no final da década de 1980 (MONTAGNA et al., 2012, p.98.).

A institucionalização da Política Nacional de Resíduos Sólidos com a lei Federal $\mathrm{n}^{\circ}$ 12.305/2010 tornou-se um importante instrumento para incentivar o desenvolvimento da gestão de resíduos no Brasil e no enfrentamento dos principais problemas ambientais, sociais e econômicos decorrentes do manejo inadequado dos resíduos.

Para Araújo et al. (2015, p.2) a composição dos resíduos sólidos urbanos de uma localidade depende de aspectos socioeconômicos, culturais e geográficos, como, por exemplo o poder aquisitivo, atividade econômica predominante, presença ou não de indústrias e hábitos de vida etc.

A natureza dos resíduos produzidos atualmente mudou nos últimos 20 anos tanto em volume quanto em composição. A excessiva utilização de embalagem nos produtos consumidos é uma das maiores fontes de resíduos domésticos (BERNARD; MILDRED, 2015, p. 2). O grande número de embalagens plásticas contribui para 0 aumento do volume nos aterros controlados ou lixões, resultando na necessidade de maiores áreas e veículos com capacidade de compactação para seu transporte (PEREIRA, 2012, p.3233).

De acordo com ABRELPE, Associação Brasileira de Empresas de Limpeza Pública e Resíduos Especiais (2012, p.1) em pesquisa realizada pelo banco Mundial, $51 \%$ dos resíduos domiciliares gerados no Brasil correspondem a matéria orgânica. Em 2014 o Brasil gerou aproximadamente 78,6 milhões de toneladas de resíduos, o que representa um aumento de 2,9\% em comparação com o ano de 2013, este índice é superior à taxa de crescimento populacional no país $(0,9 \%$.) no mesmo período de (ABRELPE, 2014, p.1).

\section{A Coleta Seletiva e a Reciclagem}

A coleta seletiva é uma atividade relativamente recente no Brasil, exercendo papel fundamental no equilíbrio do planeta, tendo em vista que reduz a extração dos recursos naturais de maneira desenfreada, diminui a poluição do solo, água e do ar possibilitando a aproveitamento de materiais que posteriormente poderiam vir a ser jogados em locais impróprios (SOUZA, 2011).

A coleta de resíduos sólidos previamente segregados conforme sua constituição ou composição, ou no mínimo, em duas frações: secos e úmidos, constitui uma prática de disposição final ambientalmente adequada dos rejeitos. De acordo com a ABRELPE $(2014$, p.1) menos de $65 \%$ dos municípios Revbea, São Paulo, V. 13, № 2: 228-245, 2018. 
contam com iniciativas de coleta seletiva. Entretanto muitas vezes estas iniciativas não abrangem totalmente a população e caracteriza-se apenas em disponibilizar pontos de entrega voluntária.

As cooperativas de catadores de materiais recicláveis são fundamentais na cadeia de reciclagem. Lundgreen (2012, p.27) salienta a composição da cadeia de reciclagem, onde atuam organizações formais, informais e catadores independentes movimentando volumes crescentes de resíduos de volta para o processo produtivo.

Este sistema vem sendo implantado de forma específica por grupos de cidadãos independentes de empresas ou do poder público, ou cooperativas de pequeno porte, o que torna difícil a garantia de condições de trabalho satisfatórias para estes indivíduos (BRINGHETI; GÜNTHER, 2011, p.428-429).

Os resíduos podem ser considerados como nada, entretanto constituem material útil no lugar errado (DESA, KADIR, YUSOOFF, 2012, p.1). Nesse contexto, Maia et al. (2013, p. 357) evidenciam que a reciclagem é uma das soluções para o tratamento dos resíduos urbanos, correspondendo ao processo pelo qual se faz novos objetos a partir de coisas usadas contribuindo para benefícios ambientais e econômicos. A percepção da importância da reciclagem vai além da valoração econômica, tendo em vista que, essa atitude contribui para uma melhor qualidade de vida e um país mais responsável com seus resíduos.

$\mathrm{Na}$ tentativa de se obter um bom resultado na melhoria do meio ambiente, tem se sugerido a pedagogia dos 5 R's: refletir, recusar, reduzir, reutilizar e reciclar (COMINI et al., 2009, p.1-3.).

Oliveira et al. (2013, p.6-8.) salienta que o primeiro passo é reduzir os resíduos produzidos, agregando a estes maior longevidade e durabilidade são condições importantes para a redução. Outra meta importante é a reutilização de muitos dos objetos do cotidiano, com a reciclagem transformando materiais inúteis em novos produtos ou matérias-primas, de forma a diminuir a quantidade de resíduos que seria descartado, poupando energia e recursos naturais valiosos, reduzindo assim a quantidade de materiais virgens necessários à produção de novos produtos.

\section{Percepção Ambiental}

A percepção ambiental está intimamente ligada à cultura, história, tempo e experiência de cada pessoa (SUESS; BEZERRA; SOBRINHO, 2013). A percepção expressa os sentimentos, valores e atitudes, como o indivíduo olha 0 ambiente, resultando em ações sobre o espaço em que vive. Fernandes (2004, p.2) destaca que uma das dificuldades para a proteção dos ambientes naturais, está na existência de diferenças nas percepções e esta percepção pode ser utilizada para avaliar a degradação ambiental de uma determinada região. 
A percepção ambiental inadequada da realidade reflete na atividade humana desenfreada, no uso abusivo de recursos naturais, no consumismo exacerbado, promovendo a utilização dos recursos de maneira insustentável comprometendo a estabilidade ambiental e social (SILVA; LEITE, 2008, p.379). A percepção de que os recursos naturais são infindáveis e o desconhecimento da capacidade de suporte dos sistemas naturais desencadeou a cultura do desperdício e a transformação de recursos naturais em resíduos (OLIVEIRA; SILVA, 2007, p.213).

O consumismo da sociedade moderna é o principal causador de agravos ao ambiente, contribuindo para a poluição, e muitas vezes os consumidores não se conscientizam e não entendem que estão se prejudicando diretamente (GUIMARÃES; VIANA; COSTA, 2015, p. 97).

Estes estudos são importantes para identificar as formas precisas, em que a educação ambiental poderá sensibilizar e trabalhar as dificuldades ou dúvidas que os sujeitos possam vir a ter, quando discutidas as questões ambientais (KLERING; KRUEL; STRANZ, 2012).

Desta forma, investigar a percepção ambiental configura uma estratégia importante, na medida que, colabora com as ações individuais e coletivas para conscientização e compreensão das inter-relações entre 0 homem e 0 ambiente, na medida que os próprios indivíduos que estão inseridos no processo, não venham interferir negativamente na sua qualidade de vida.

\section{Procedimentos Metodológicos}

A metodologia de pesquisa utilizada neste trabalho está fundamentada em uma abordagem qualiquantitativa e explicativa com caráter descritivo. Minayo (2011, p.26) esclarece que a abordagem qualitativa atuará na compreensão, na inteligibilidade dos fenômenos sociais, no significado preliminarmente quanto a percepção ambiental e a intencionalidade que the atribuem os atores.

A abordagem quantitativa compreende que a coleta de dados de escores ou informações conversíveis em números (percentuais) que permitam verificar a ocorrência ou não das consequências (MOREIRA, 2004, p.109).

As técnicas de coleta de dados consistiram em entrevistas semiestruturadas, composta por um total de 10 perguntas, sendo 7 questões objetivas e 3 questões abertas. As questões abordaram aspectos voltados para a ação ambiental como: redução, reutilização, separação e reciclagem dos resíduos.

A aplicação do questionário se deu no período de julho a novembro de 2014. As questões refletem o dia a dia dos pesquisados, levando em consideração aspectos ligados ao cotidiano das rotinas e à percepção em relação ao assunto, podendo ser facilmente avaliados para subsidiar as ações futuras. 
Utilizou-se a estratégia de aplicar os questionários junto aos atores sociais conforme os mesmos recebiam a visita do ACE (Agente de Combate ás Endemias), em virtude da acessibilidade de contato com os entrevistados.

As Perguntas objetivas receberam um tratamento quantitativo, agrupando os dados em gráficos, sequenciado por interpretação e descrição. As Perguntas subjetivas inicialmente serão agrupadas em categorias de respostas e depois quantificadas em gráficos.

Os resultados foram organizados em gráficos, de acordo com categorias e analisados a partir do Microsoft Excel 2003.

\section{Recorte geográfico do estudo}

A população do estudo concentrou-se nas famílias residentes no bairro Santo Antônio, zona urbana de São Sebastião de Lagoa de Roça cidade da Microrregião do Agreste Paraibano. Foi utilizada uma amostra de 60 entrevistas correspondente a $15 \%$ do universo das famílias residentes do bairro Santo Antônio.

A escolha desse público-alvo se deu pela peculiaridade relacionada ao contexto em que as famílias estão inseridas, ou seja, problema ambiental evidente, quanto ao descarte inadequado de resíduos sólidos feito pelos moradores nas ruas da cidade.

\section{Resultados e Discussão}

As questões a seguir abordam os aspectos referentes ao perfil socioeconômico dos entrevistados. Na Figura 1 encontra-se a distribuição por gênero.

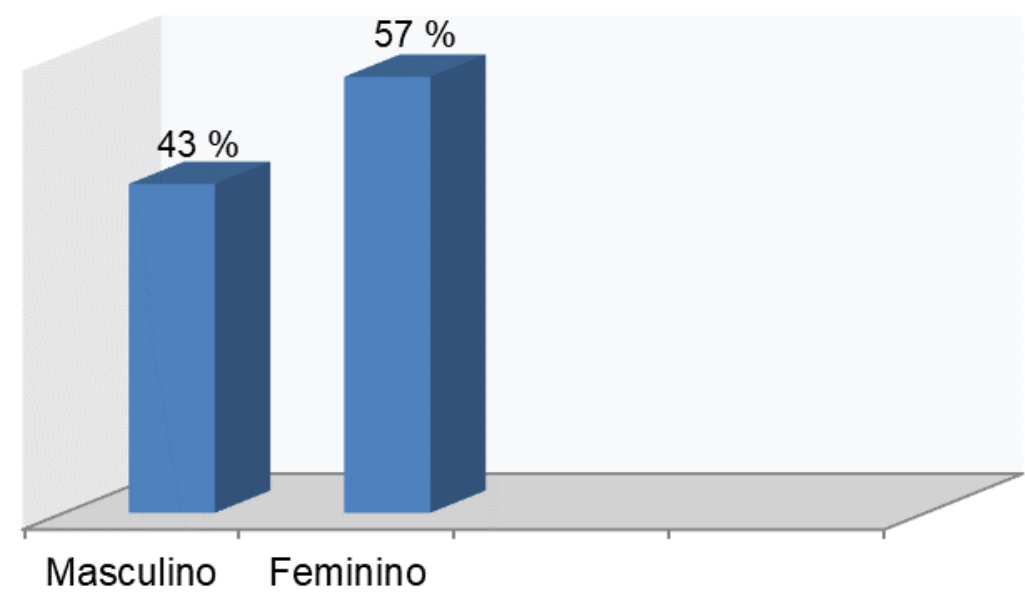

Figura 1: Distribuição dos entrevistados por gênero.

Fonte: Pesquisa de campo, 2014. 
Observa-se a predominância do sexo feminino (57\%) sobre o masculino (43\%), houve maior participação do gênero feminino, tendo em vista que as donas de casa encontram-se em seus domicílios na maior parte do tempo e os questionários foram aplicados no período da manhã.

Em relação à idade dos entrevistados é possível observar que a mesma variou entre 15 e 60 anos (Figura 2).

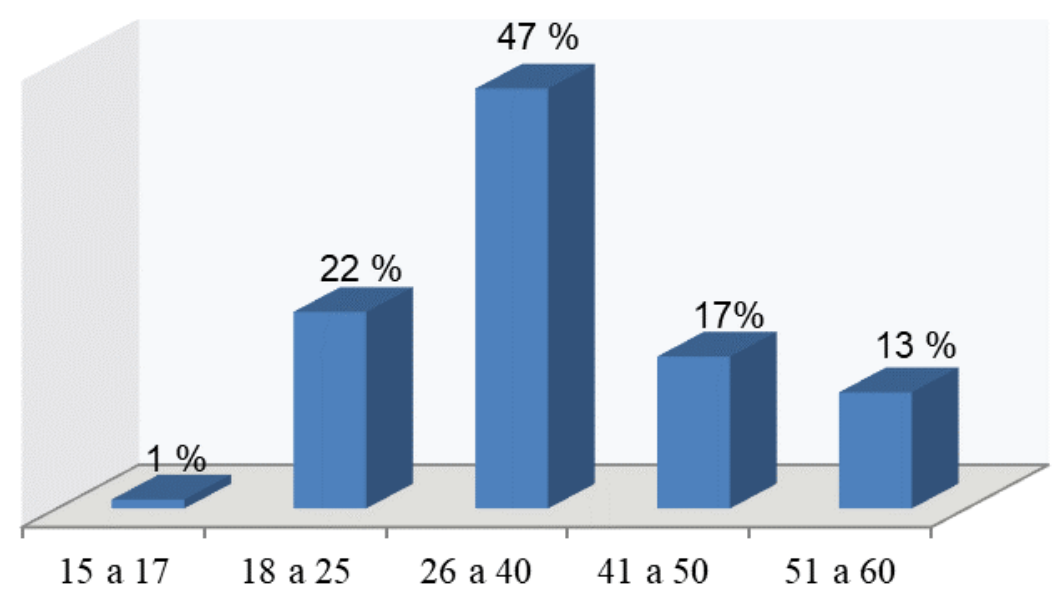

Figura 2: Distribuição da população quanto à faixa etária.

Fonte: Pesquisa de campo, 2014.

$\mathrm{Na}$ distribuição dos entrevistados por faixa etária, identificou-se a predominância de 26 a 40 anos de idade com $47 \%$, 18 a 25 anos $22 \%, 41$ a 50 anos $17 \%$, revelando assim uma população relativamente jovem. Mas os idosos também tiveram uma participação considerável, de 51 a 60 anos expressam $13 \%$ dos entrevistados. E com menor participação com $1 \%$ os jovens de 15 a 17.

Na Figura 3 está ilustrado os resultados quanto ao nível de escolaridade dos entrevistados. De modo geral, o universo pesquisado apresenta um grau de instrução que varia entre ensino fundamental incompleto $(45 \%)$, ensino médio completo (25\%), ensino superior incompleto (10\%), com $7 \%$ ensino superior completo, ensino médio incompleto (5\%), ensino técnico $5 \%$ e ensino fundamental completo (2\%) e pós-graduado $1 \%$. Esta variável permite avaliar o comportamento de uma população, pois através do domínio do conhecimento, o indivíduo se torna mais crítico e passa a exercer de maneira mais adequada seu papel de cidadão (BARRETO et al., 2008). 


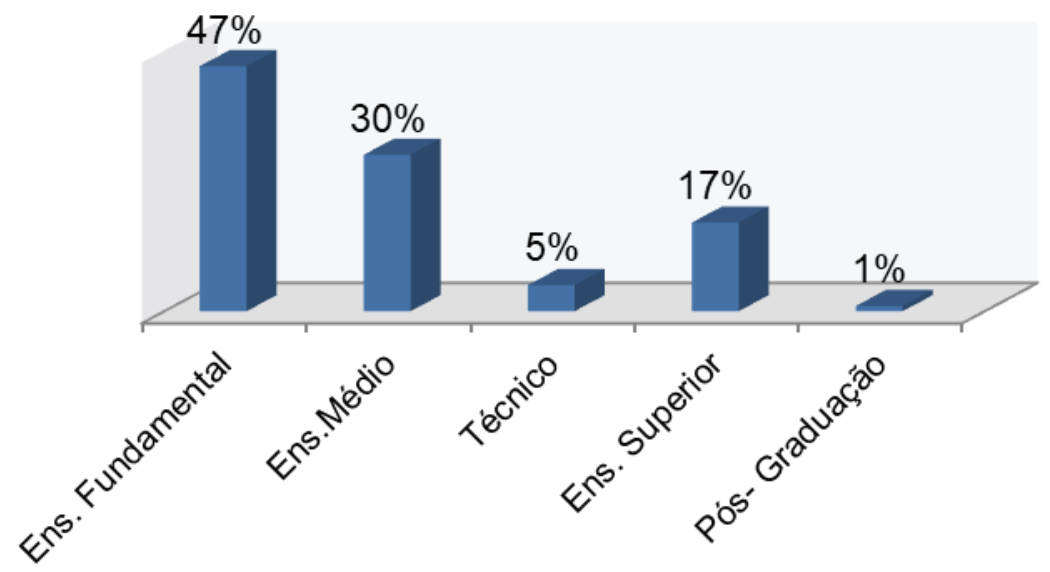

Figura 3: Distribuição da população quanto ao nível de escolaridade.

Fonte: Pesquisa de campo, 2014.

$\mathrm{Na}$ Figura 4 está apresentada as respostas com relação o número de pessoas residentes em cada domicílio. Esse enfoque ganha valor, ao tomarmos por base o que afirma Araújo et al. (2009, p. 67-72), ao considerar que as pessoas que residem no local/área afetada são, ao mesmo tempo, causadoras e vítimas de parte dos problemas impactantes da região afetada, e são estas que convivem com os problemas.

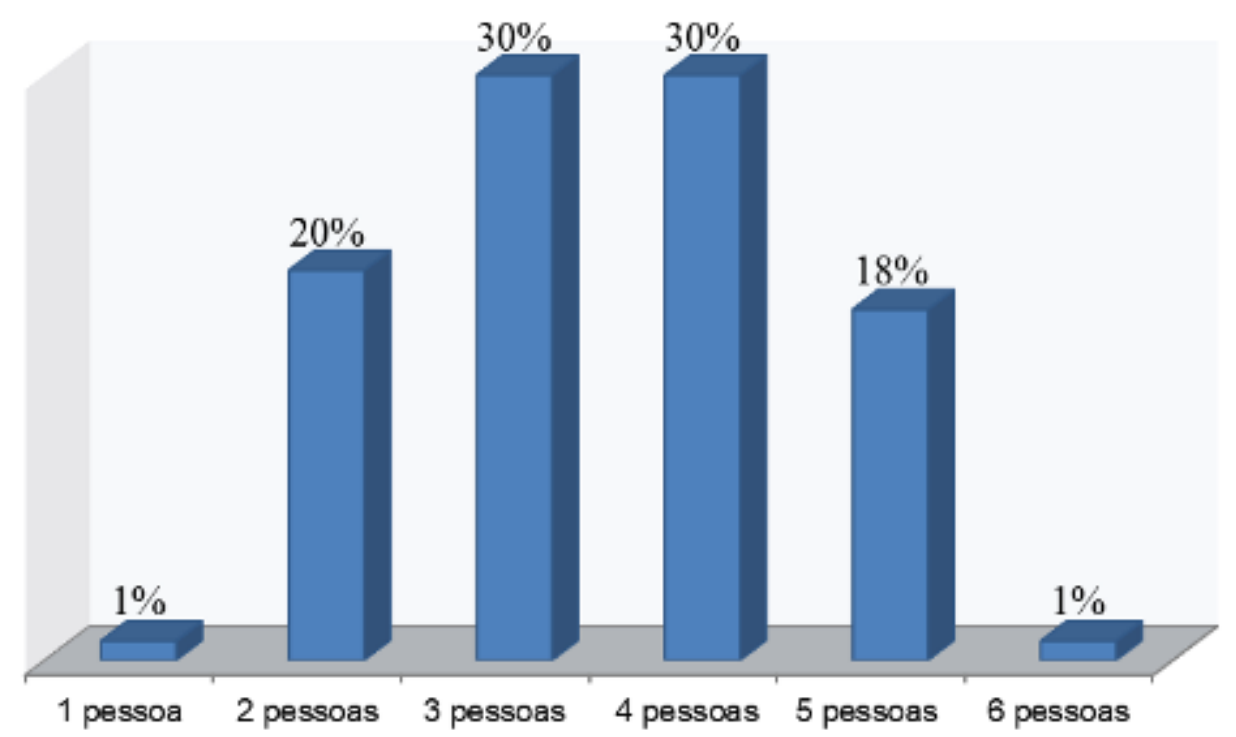

Figura 4: Número de pessoas que moram na mesma residência.

Fonte: Pesquisa de campo, 2014.

Os resultados apresentados mostram que grande parcela das residências, são habitadas por três e quatro pessoas com mesmo percentual de $30 \%$ para cada variável, $20 \%$ com 2 pessoas ,18\% apresenta cinco

Revbea, São Paulo, V. 13, № 2: 228-245, 2018. 
pessoas, $1 \%$ tem seis pessoas e também com o percentual de $1 \%$ uma pessoa residindo sozinha. Quanto maior de número de pessoas de uma residência e dependendo do comportamento destes, influenciará na dimensão dos impactos a serem causados pela geração e destinação dos resíduos.

Ao serem questionados: "O que vem a sua mente quando você pensa em "lixo"?" (Figura 5). Predominou nesta variável a percepção de repulsa e inutilidade ao serem somados os percentuais referentes a sujeira, doença, poluição, o que não presta, totalizaram aproximadamente $86 \%$ das respostas.

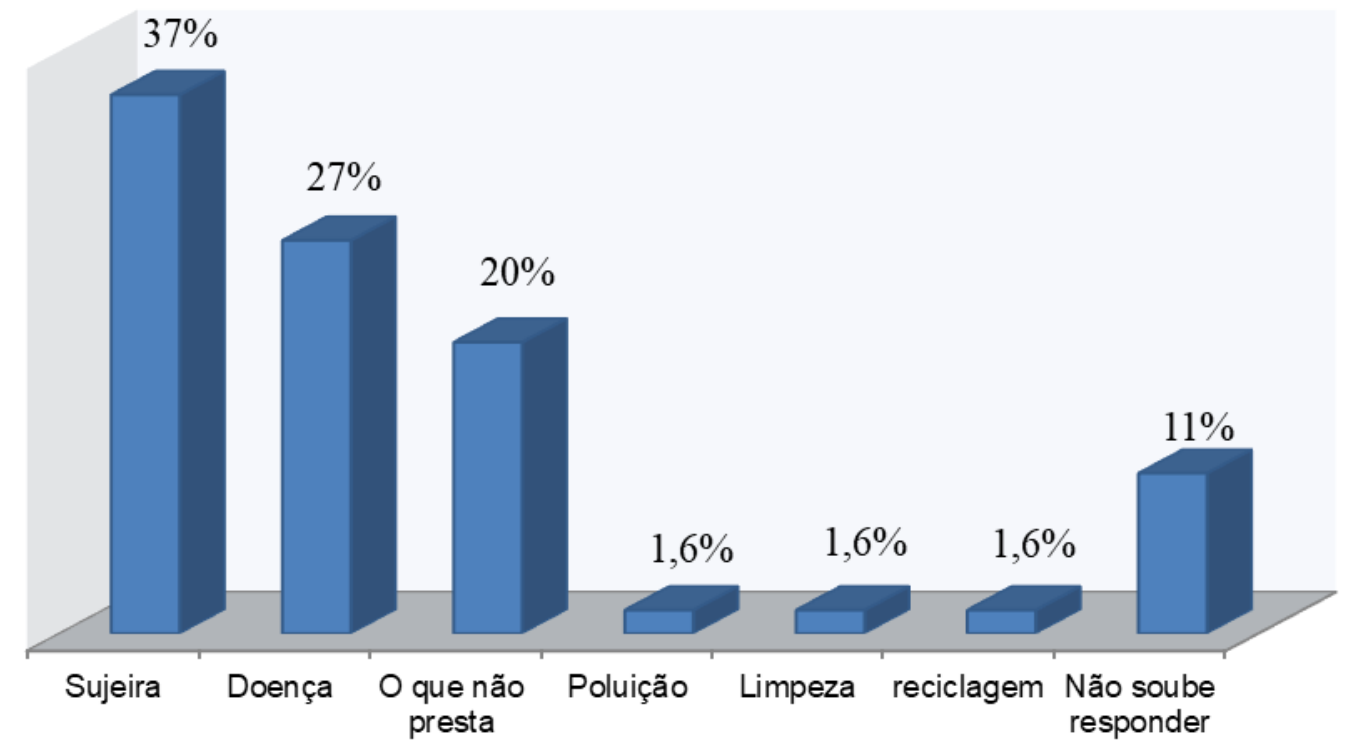

Figura 5: Percepção dos entrevistados quanto ao "lixo".

Fonte: Pesquisa de campo, 2014.

Visando caracterizar os resíduos domésticos realizou se o seguinte questionamento: "Quais são os materiais mais encontrados no "lixo" da sua casa?" (Figura 6). Como pode ser observado, o plástico foi o material mais citado como sendo encontrado nos resíduos domiciliares dos entrevistados com percentual de $54 \%$, resto de alimentos com $17 \%$, papel $16 \%$, fraldas descartáveis $5 \%$, papel sanitário $3 \%$, latinhas $2 \%$, folhas $2 \%$ e $1 \%$ as pessoas que não souberam responder. Atualmente, as sacolas plásticas representam $10 \%$ de todo os resíduos produzido no Brasil, e cada brasileiro utiliza cerca 19 quilos de sacolas por ano (OLIVEIRA et al., 2012, p.8). 


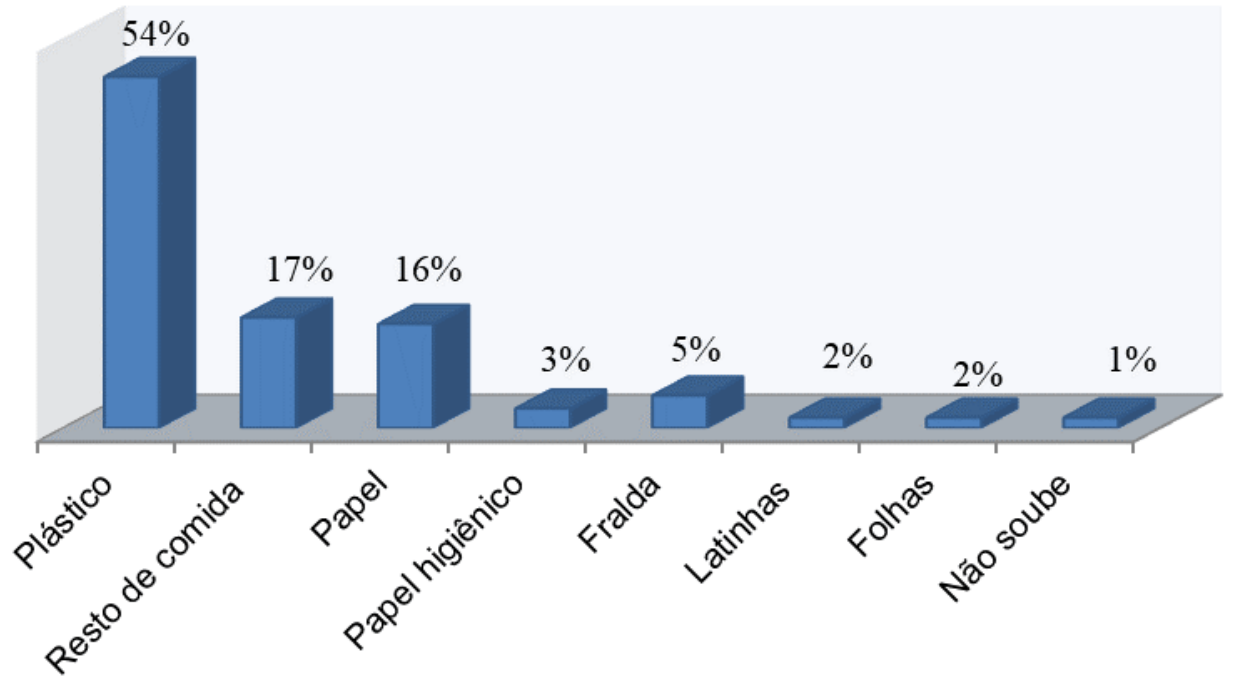

Figura 6: Descrição dos resíduos produzidos nos domicílios.

Fonte: Pesquisa de campo, 2014.

O uso de plásticos pela sociedade contemporânea está cada vez mais acentuado, e esse uso demasiado em excesso tem trazido sérios problemas ambientais ao mundo moderno (NETO et al., 2011, p.55-70).

Outro questionamento foi realizado, à percepção dos entrevistados referente a quantidade de resíduos gerados em suas residências. Esta análise permite observar a passividade em relação aos resíduos que produzem, $73 \%$ responderam não preocupar-se e $27 \%$ responderam estar preocupados com a quantidade de resíduos gerados em suas residências.

Quando questionados se no momento da aquisição de produtos levam em consideração aqueles que geram menos resíduos (Figura 7 ), $72 \%$ dos entrevistados, afirmaram não possuir esse tipo de preocupação e $28 \% \operatorname{sim}$.

A preocupação que as pessoas tem com os resíduos sólidos é ínfima, parecendo não fazer parte do seu cotidiano, os entrevistados afirmaram que, pelo menos, até aquele momento não haviam refletido sobre o potencial poluidor de algumas embalagens. 


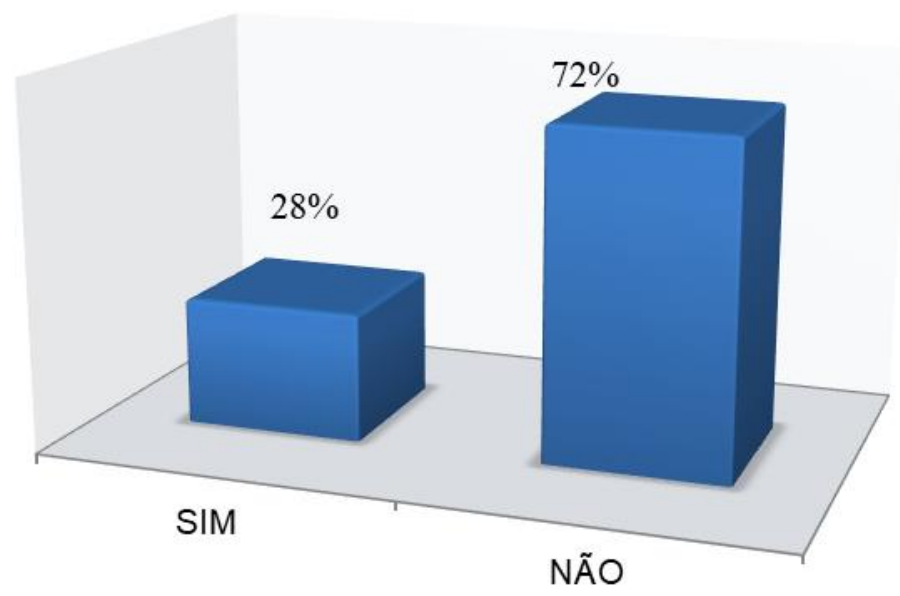

Figura 7: Disposição em adquirir produtos que geram menos resíduos.

Fonte: Pesquisa de campo, 2014.

Para Bonelli (2010, p.130-150.) reduzir o lixo em nossas casas, implicaria em reduzir o consumo de tudo o que não nos é realmente necessário. Isto significa rejeitar produtos com embalagens plásticas e isopor preferindo as de papelão que são recicláveis, que não poluem o ambiente (Figura 8), e desperdiçam menos energia.
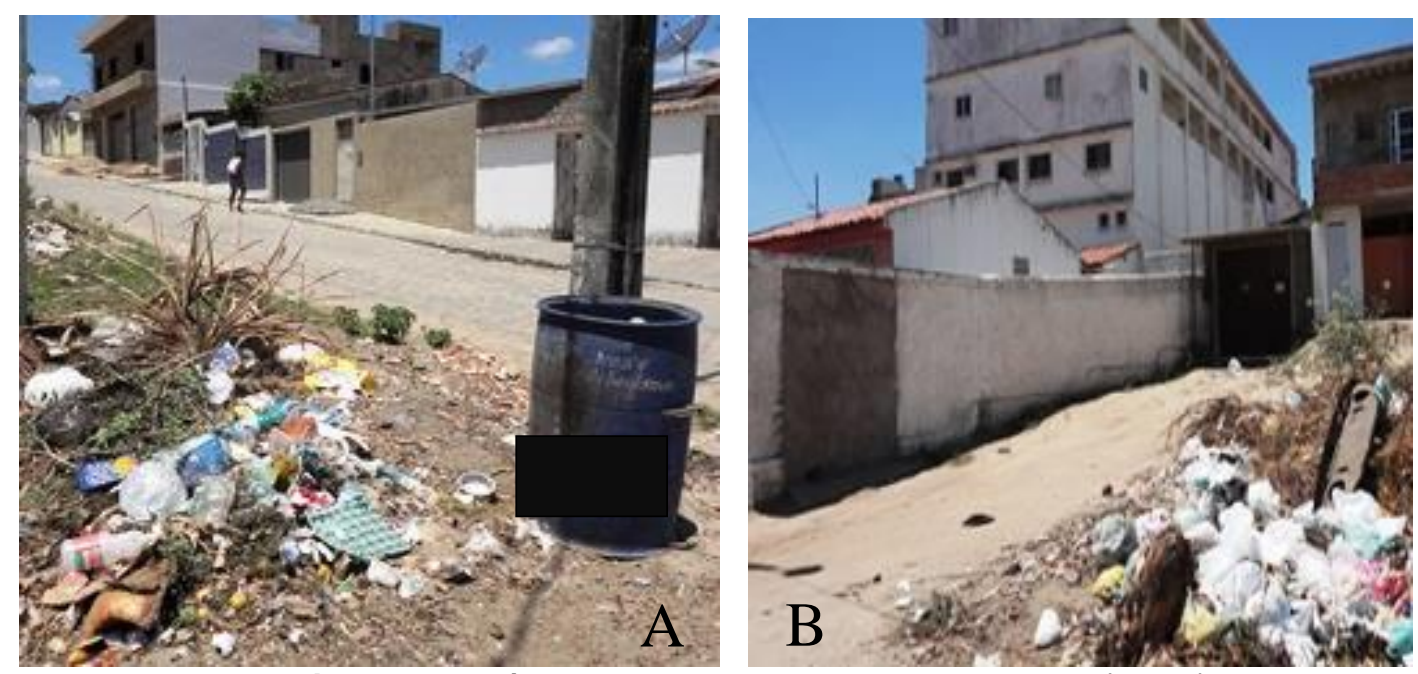

Figura 8: Resíduos depositados nas ruas da cidade ( $\mathrm{A}$ e $\mathrm{B})$.

Fonte: Pesquisa de campo, 2014. 
reaproveitamento para os resíduos produzidos e $27 \%$ não veem esta possibilidade.

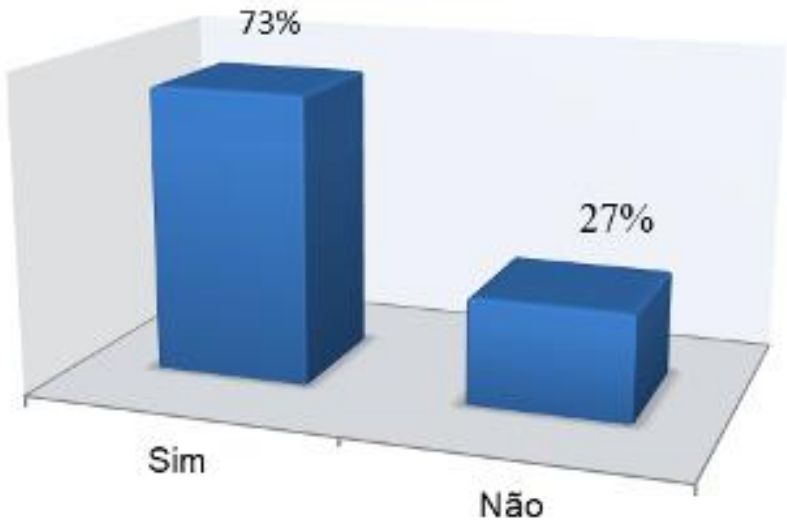

Figura 9: Percepção de reaproveitado dos resíduos.

Fonte: Pesquisa de campo, 2014.

Para Fadini e Fadini (2011, p.1), o reaproveitamento desses resíduos antes que eles sejam descartados diminui sua quantidade a ser aterrado, preservando os recursos naturais, economizando energia, diminuindo a poluição do ar e da água, além de beneficiar a população gerando ocupação e renda através da criação de postos de trabalho e indústrias de recicláveis.

Baseado nas respostas supracitadas o Figura 10, apresenta o resultado referente a potencialidade do reaproveitamento dos resíduos. Assim, foi constatado que, $31 \%$ indicou garrafas PETs, $11 \%$ adubo, $8 \%$ sabão, $6 \%$ reciclagem, $3 \%$ plástico, $3 \%$ artesanato, $3 \%$ papel. No entanto, um percentual $35 \%$ não soube responder como os resíduos podem ser reaproveitado.

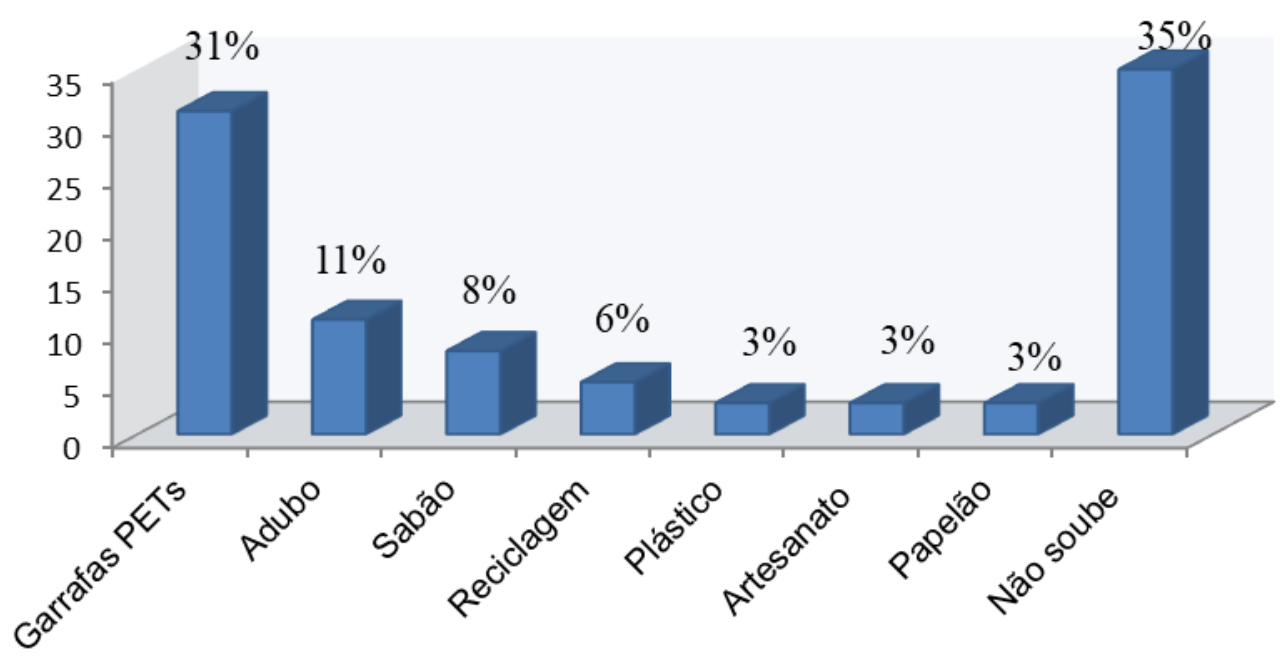

Figura 10: Sugestões de reaproveitamento de resíduos.

Fonte: Pesquisa de campo, 2014. 
Buscando avaliar os conhecimentos sobre a coleta seletiva, os entrevistados foram perguntados sobre esta atividade (Figura 11). Diante deste questionamento $67 \%$ dos entrevistados afirmaram saber o significado de coleta seletiva e $33 \%$ não sabem.

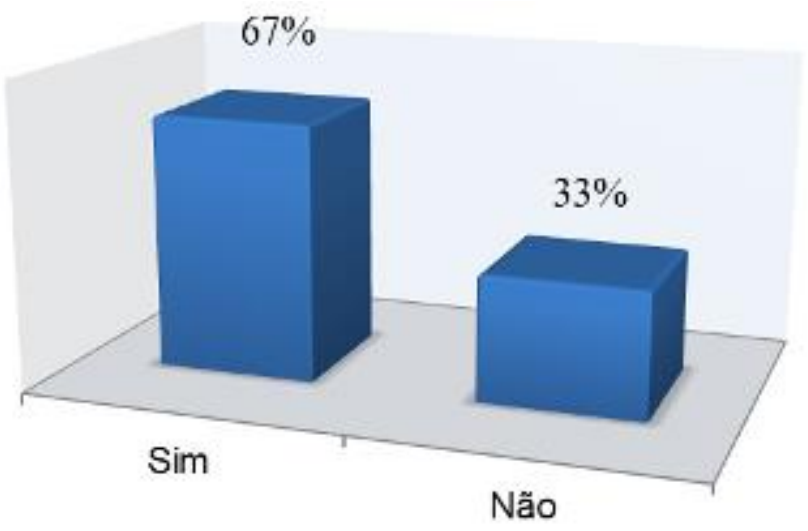

Figura 11: Conhecimento sobre o termo coleta seletiva.

Fonte: Pesquisa de campo, 2014.

Sabe-se que a Coleta Seletiva é um dos principais instrumentos de intervenção na realidade socioambiental (TRINDADE, 2011, p.7). A coleta seletiva é um instrumento que incentiva a redução, à reutilização e separação dos materiais para reciclagem, o que diminui consequentemente os desperdícios relativos ao consumo.

Outra questão analisada enfoca o conhecimento dos entrevistados em relação a existência de locais para entrega voluntária de resíduos. A maioria dos entrevistados $57 \%$ relataram existir pontos para coleta de resíduos, 33\% consideraram não haver e $10 \%$ não souberam responder. Mesmo diante da expressividade de um percentual acreditar na existência de pontos de entrega dos resíduos recicláveis, o município conta apenas com catadores de materiais recicláveis que fazem a catação dos resíduos informalmente na cidade e armazenam em suas residências (Figura 12).
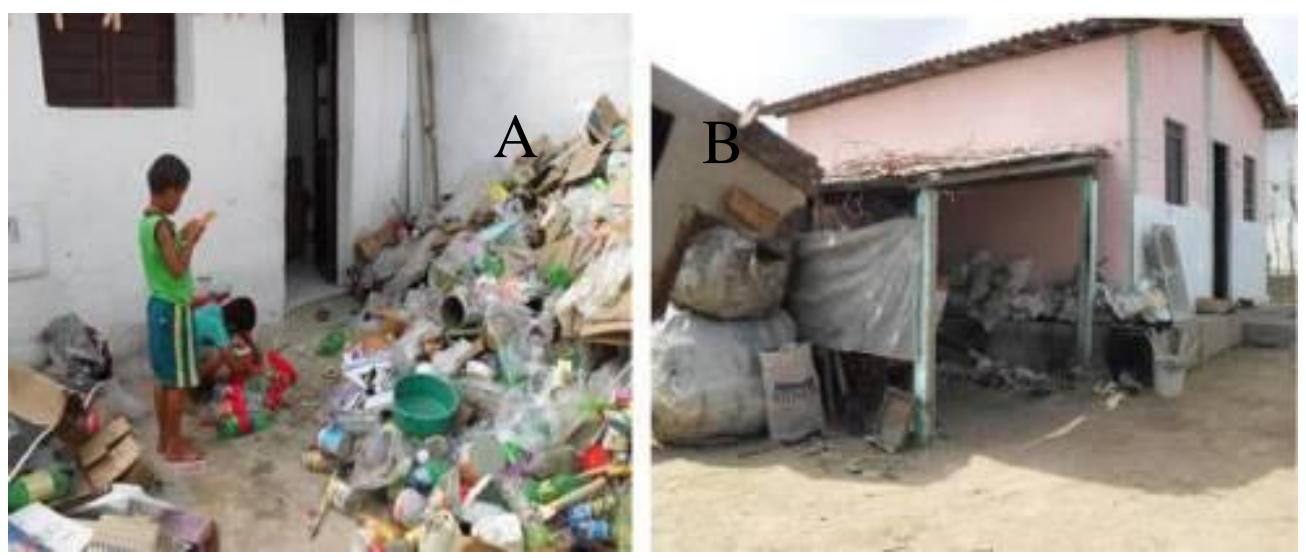

Figura 12: Residência de catadores de materiais recicláveis ( $A$ e $B$ ).

Fonte: Pesquisa de campo, 2014. 
Outra variável analisada refere-se à separação dos resíduos nas residências, uma parcela considerável da amostra $60 \%$ dos entrevistados não fazem nenhum tipo de separação, $40 \%$ separam os resíduos. Entre estes que realizam a separação dos resíduos, afirmaram separar apenas o lixo orgânico dos demais resíduos destinados a catadores que realizam esta atividade como ocupação informal na cidade.

Santos et al. (2011, p.6), reforça que para a realização da coleta seletiva é necessário o envolvimento da administração municipal para garantir a eficiência dos serviços de coleta, juntamente com a participação ativa popular local com hábitos adequados ao serviço colaborando no acondicionamento do resíduos sólidos, nos dias e horários e colaborando e agindo como fiscais nos serviços prestados em prol do sucesso coletivo e ambiental.

Diante da existência de moradores que realizam a coleta de materiais recicláveis na cidade como meio de sobrevivência. No Figura 13 tem-se apresentado os resultados da percepção dos moradores sobre a importância deste trabalho.

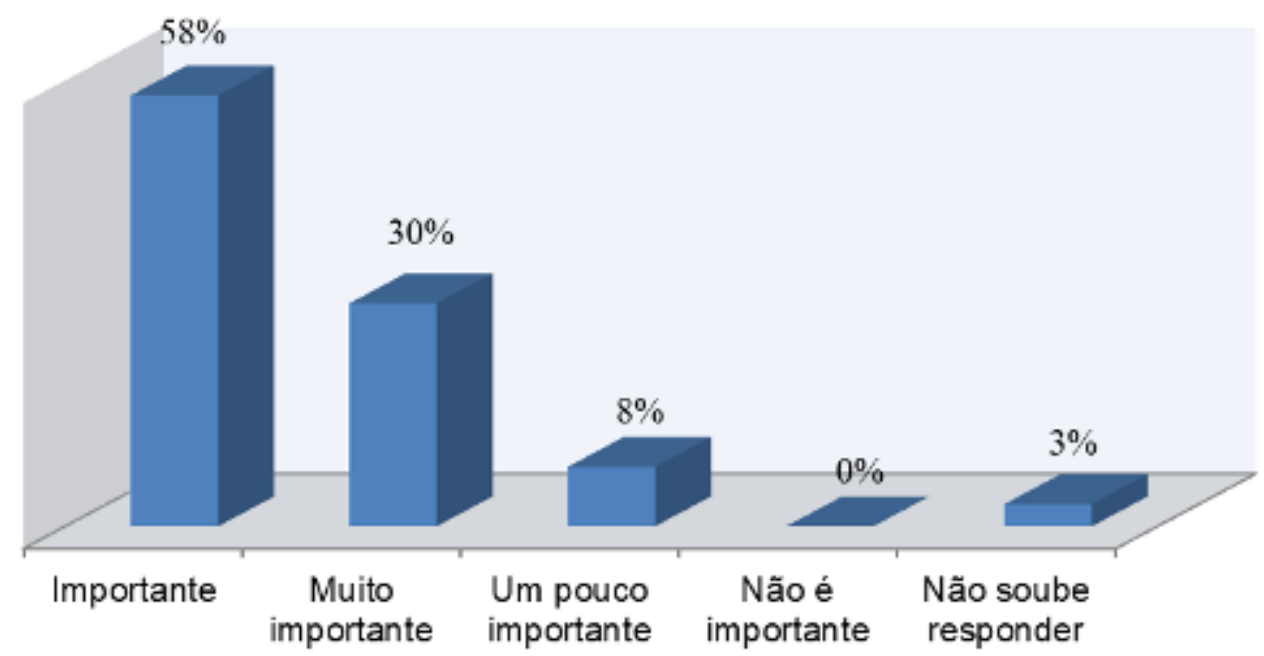

Figura 13: Importância da atuação dos catadores de materiais recicláveis.

Fonte> Pesquisa de campo, 2014.

É pertinente observar que para $88 \%$ dos entrevistados percebe a importância do trabalho realizado pelos catadores de materiais recicláveis, contra $8 \%$ que considerou pouco importante. E apenas $3 \%$ não soube responder.

O trabalho realizado por estes trabalhadores consiste em catar, separar, transportar, acondicionar e, às vezes, beneficiar os resíduos sólidos com valor de mercado para reutilização ou reciclagem. É por este processo que ocorre a ressignificação do "lixo" em mercadoria (BENVINDO, 2010, p.69-79). Constatase no município apenas a catação e venda a atravessadores. 


\section{Considerações finais}

Diante dos resultados obtidos observou que a maioria dos pesquisados possui percepção confusa, referente a redução, reutilização e reciclagem dos resíduos, não percebendo as inter-relações entre ações, hábitos e os possíveis impactos positivos ou negativos sobre o ambiente natural e social. Embora grande parte dos entrevistados tenham declarado conhecer o significado do termo coleta seletiva e considerar a possibilidade de reaproveitamento dos resíduos domésticos, e ainda caracterizando como importante o trabalho dos catadores de materiais recicláveis.

É notório a necessidade de mudança de postura, já que os mesmos expressaram a percepção de repulsa e inutilidade sobre os resíduos, como também não são sensíveis a quantidade de resíduos que geram em suas residências, e ainda não consideram a possibilidade de adquirir produtos geram menos resíduos, não percebendo o potencial poluidor de algumas embalagens.

Está análise permite observar a passividade em relação a redução, reutilização e reciclagem dos resíduos. As atitudes negativas podem ser associada ao conhecimento ambiental insuficiente, que reflete no comportamento expressado pelos entrevistados.

Os padrões de gestão de resíduos da cidade ainda são insuficientes, apesar da complexidade e seriedade da abordagem da produção e gerenciamento dos resíduos domésticos. Para tanto, faz-se necessário a implantação um PGRS (Plano de Gerenciamento de Resíduos Sólidos) com métodos sustentáveis relevantes, políticas de intervenção e sensibilização ambiental, que contribuam à mudança de hábitos, comportamento e incentivem a participação da comunidade na gestão de resíduos domiciliares possibilitando qualidade Ambiental satisfatória.

\section{Referências}

ABRELPE - Panorama dos Resíduos Sólidos no Brasil 2012, p.1 Disponível em: <http://www.abrelpe.org.br/panorama apresentacao.cfm>. Acesso em: 05 maio 2014.

ABRELPE- Panorama dos Resíduos Sólidos no Brasil 2014, p. 1. Disponível em: <http://www.abrelpe.org.br/Panorama/panorama2014.pdf. > Acesso em: 12 dez. 2014.

ARAÚJO, N.C. et al. Gravimetria e abordagem econômica dos resíduos sólidos urbanos do município de Barra de São Miguel - Paraíba. Revista Eletrônica em Gestão, Educação e Tecnologia Ambiental, v. 19, n. 3, p. 67-72,set-dez. 2009. Disponível em:<https://periodicos.ufsm.br/reget/article/ viewFile/17584/pdf>. Acesso em: 18 nov. 2015 
ARAÚJO, L E.; SOUSA, F.A.S.; NETO, J.M.M.; SOUTO, J.S. Bacias Hidrográficas e Impactos Ambientais. Qualit@s Revista Eletrônica, V.8, n. 1. 2009, p.2; Disponível em <http://revista.uepb.edu.br/index.php/qualitas/article/ view/399/366 >Acesso em: 18 ago. 2017.

BENVINDO, A.Z. A nomeação no processo de construção do catador como ator econômico e social. 2010. 95 f., p. 69-79 Dissertação (Mestrado em Ciências Sociais)- Universidade de Brasília, Brasília, 2010.

BERNARD, O.; MILDRED, O.A. Assessing Household Solid Waste Management Systems In Baraton Centre. 2015, p 2. Disponível em: < http://ueab.ac.ke/BIRJ/download/birj articles 2015/2015 CONFERENCE 17.p df $>$. Acesso em: 14 out. 2015.

BONELLI, C.M.C. Meio ambiente, poluição e reciclagem, 2 ed. Blucher, São Paulo: 2010, p.130-150.

BRINGHENTI, J.R.; GUNTHER, W.M.R. Participação social em programas de coleta seletiva de resíduos sólidos urbanos. Engenharia Sanitária e Ambiental. Volume 16, out./dez. 201, p.428-429.

COMINI, et al. Digressão sobre a inserção da variável sustentabilidade socioambiental no planejamento estratégico das organizações. Revista Tenda, CEFET/RJ, n. 3. 2007, p.1-3.

DINIZ. A.S. A problemática dos resíduos sólidos urbanos em São Sebastião Roça de Lagoa de - PB. Revista Brasileira de Informações Científicas, v. 2, n. 3, jul./set. 2011, p. 42-43. Disponível em: < http://livrozilla.com/doc/369523/aproblem\%C3\%A1tica-dos-res\%C3\%ADduos-s\%C3\%B3lidos-urbanos-ems\%C3\%A3o> Acesso em: 3, ago 2017.

DESA, A.; KADIR, B.A.; YUSOOFF, F. Environmental Awareness and Education: A Key Approach to Solid Waste Management (SWM) - A Case Study of a University in Malaysia. 2012 p. 1 Disponível em:<http://cdn.intechopen.com/pdfs/40498/InTechEnvironmental awareness a nd education a key approach to solid waste management swm a case st udy of a university in malaysia.pdf >. Acesso em: 10 out. 2014.

FADINI, P.S.; FADINI, A.A.B. Lixo: desafios e compromissos. Cadernos temáticos de química nova na escola. Edição especial. p. 9-18, maio 2011.

FAGGIONATO, S. Percepção ambiental, p.1. Disponível em: http://ambientes.ambientebrasil.com.br/educacao/artigos/percepcao ambiental. html Acesso em: 03 ago. 2017.

FERNANDES, R.S. et al. Uso da Percepção Ambiental como Instrumento de Gestão em Aplicações ligadas às Áreas Educacional, Social e Ambiental. 2004. p.2. Disponível em: $<$ http:// www. redeceas. esalq.usp.br/noticias/Percepcao Ambiental.pdf >. Acesso em: 12 Jul. 2014. 
GUIMARÃES, C.; VIANA, L.S.; COSTA, P.H.S. Os Desafios da Consciência Ambiental: o marketing verde em questão. Cadernos de Aulas do LEA. n. 4, p.97. 2015. Disponível em:< http://www.uesc.br/revistas/calea/ edicoes/rev4artigo7.pdf>. Acesso em: 18 nov. 2016.

LUNDGREN, K. The global impact of e-waste: addressing the challenge International Labour Office, Programme on Safety. Geneva, 2012, p.27.

MAIA, H. J. L.; et al. Coleta Seletiva: Benefícios da sua Implantação no bairro de Santa Rosa, Campina Grande-PB. POLÊM!CA, v. 12, n. 2, 2013, p. 357. Disponível em: <http://www.e-publicacoes.uerj.br/index.php/polemica/article /view/6437/4845>. Acesso em: 18 nov. 2014.

MINAYO, M.C.S. (org.). Pesquisa social: teoria, método e criatividade. 30. ed. Petrópolis. RJ: Vozes, 2011. p. 26.

MOREIRA, D.A. O método fenomenológico na pesquisa. 3. ed. São Paulo: Pioneira Thomson, 2004, p. 109.

MONTAGnA, A. et al. Curso de Capacitação. Plano Municipal de Gestão Integrada de Resíduos Sólidos: planejamento e gestão. Florianópolis: AEQUO: 2012. 98p.

NETO, P.H.H. et al. Sacolas Plásticas: Consumo Inconsciente. Perspectivas Online: Biológicas e Saúde. V. 1, no 3, 2011; p . 55-70; Disponível em: $<$ https://doaj.org/doaj?func=abstract\&id $=1082913 \&$ recNo=6\&toc $=1$ \&uilanguage $=$ en>. Acesso em: 22 abr 2014.

OLIVEIRA, L.L. et al.; Impactos Ambientais Causados pelas Sacolas Plásticas: O Caso Campina Grande - PB. BIOFAR: Revista de Biologia e Farmácia. v. 7, n. 1. p.88 -103. 2012. Disponível em: < http://sites.uepb.edu.br/ biofar/download/v7n12012/impactos ambientais causados pelas sacolas pla sticas.pdf>. Acesso em: 5 out. 2014.

OLIVEIRA, R.C. et al. Resíduos Sólidos Urbanos: Legislação e Novos Desafio. 2013, p 6-8 Disponível em: < http://www.academia.edu/7620855/RES\%C3\%8DDUOS S\%C3\%93LIDOS UR BANOS LEGISLA\%C3\%87\%C3\%830 E NOVOS DESAFIOS $>$.Acesso em: 14 de maio de 2014.

OLIVEIRA, I.S.; SILVA, M.M.P. Educação Ambiental em comunidade eclesial de base na cidade de Campina Grande: contribuição para o processo de mobilização social. Revista Eletrônica do Mestrado em Educação Ambiental, v. 18, p. 213. 2007. Disponível em: < https://periodicos.furg.br/remea/article/download/3331/1995>. Acesso em: 14 de jul. de 2014.

PEREIRA, T.A. Diagnóstico dos resíduos sólidos urbanos da cidade de Cabaceiras - PB. 2012. 65f.,p 32-33 Conclusão de Curso (Engenharia Sanitária e Ambiental)- Universidade Estadual da Paraíba, Campina Grande 2012. 
SANTOS, E L.C. Diagnóstico Ambiental do Sistema de Coleta Seletiva no Município de Senador Canedo - Goiás. 2011, p. 6. Disponível em: <http://www.ibeas.org.br/congresso/Trabalhos2011/lll-004.pdf> Acesso em: 04 jun. 2014.

Stranz, E.; Klering, L.R.; Kruel, A.J. Os pequenos municípios do Brasil - uma análise a partir de índices de gestão. Análise. Revista de Administração da PUCRS, v. 23, n.1,2012. Disponível em:<http:/revistaseletronicas. pucrs.br/ojs/index.php/face/article/download/11433/9677>. Acesso em: 16 jul. 2014.

SILVA, M.M.P.; LEITE, V.D. Estratégias para realização de educação ambiental em Escolas do ensino fundamental. Revista Eletrônica do Mestrado Educação Ambiental, v. 20, p. 379, 2008. Disponível em:<https:// periodicos.furg.br/remea/article/view/3855/2299 >. Acesso em: 16 jul. 2014.

SOUZA, M.Z.S. Percepção ambiental dos alunos de ensino fundamental II da cidade Esperança com relação aos resíduos sólidos. 2011.52 f. Trabalho de Conclusão de Curso (Graduação em Ciências Biológicas) - Universidade Estadual da Paraíba, Centro de Ciências Biológicas e da Saúde, 2011.

SUESS, R.C.; BEZERRA, R.G.; SOBRINHO, H.C. Percepção Ambiental de Diferentes Atores Sociais Sobre o Lago do Abreu em Formosa - GO. Disponível em:<http://www2.ifrn.edu.br/ojs/index.php/HOLOS/article/ view/1287/ 771>. Acesso em: 20 mar. 2014

TADESSE, T.; RUIJS, A.; HAGOS, F. Household waste disposal in Mekelle city, Northern Ethiopia. 2008, p.2. Disponível em: $<$ http://www.academia.edu/7348854/Household waste disposal in Mekelle cit y Northern Ethiopia>. Acesso em: 18 set. 2014.

TRINDADE, N.A.D. Consciência Ambiental: Coleta Seletiva e Reciclagem no Ambiente Escolar. 2011, p. 7. Disponível em: $<$ http://www.conhecer.org.br/enciclop/2011a/humanas/consciencia\%20ambient al.pdf> Acesso em: 10 jun. 2014.

TÂRTIU, V. Evaluation of attitudes and knowledge regarding municipal waste among students, Case study: Bucharest Academy of Economic studies. J. Economia. Seria Management, v. 14, n.1, p. 263-276, 2011. Disponível em: <http://www.mer.ase.ro/files/2011-1/24.pdf> Acesso em: 08 nov. 2014.

VIVEK, R.. et al. Awareness, Attitude and Practice of School Students towards Household Waste Management. Journal of Environment, v.2, p. 147-150. Disponível em: <http://www.scientificjournals.co.uk/web documents/4020624 household waste management.pdf>. Acesso em: 08 jun. 2014. 